\title{
Research on Teaching diagnosis and improvement of "Six in one" Index system in Vocational Colleges
}

\author{
Chunguang $\mathrm{Bo}^{\mathrm{a}}$, Hongcai Li ${ }^{\mathrm{b}}$, Hongna Gao ${ }^{c}$, Xiurong $\mathrm{Wu}^{\mathrm{d}}$, Hong $\mathrm{Xu}^{\mathrm{e}}$ \\ Department of Medicine, Binzhou Polytechnic College, Binzhou, 256600. Shandong, China \\ aemail:bcgxiaohe@163.com, bemail:252418973@qq.com, 'email:1248638907@qq.com \\ demail:781787155@qq.com, eemail:1071176817@qq.com
}

Keywords: Vocational College; Teaching Diagnosis and Improvement; Index System

\begin{abstract}
After several years of exploration and practice, diagnosis and improve the vocational colleges teaching work has entered a new stage. This method can strengthen the pertinence of teaching, return the core of education to strengthen teaching quality, and then realize the teaching goal. The relationship between teaching diagnosis and improvement should be clarified, the index system of teaching diagnosis and improvement should be set up reasonably, and the scientific and feasibility of the index system should be improved. This paper analyzes the present situation of teaching diagnosis and improvement in vocational colleges, analyzes the significance of the research on the index system of teaching diagnosis and improvement in vocational colleges, and puts forward the teaching diagnosis and improvement of vocational colleges. "One in one" index system construction strategy, in order to promote the development of vocational colleges teaching quality.
\end{abstract}

\section{Introduction}

Vocational colleges to carry out the teaching in the diagnosis of improvement, its starring point is the guide vocational colleges to further deepen the reform of the systems and mechanisms, the implementation of vocational colleges main body responsibility, establish long-term effective mechanism of teaching quality assurance[1].Under this background, vocational colleges should reasonably set up teaching diagnosis and improvement index, construct perfect index system of teaching diagnosis and improvement, and give full play to the main role of teaching quality assurance. To promote the quality of teaching in vocational colleges and universities.

\section{First Research on the implication of teaching diagnosis and improvement}

Diagnosis and improve the vocational colleges teaching refers to the vocational colleges based on the characteristics and positioning itself, considering the factors in the management of teaching, such as college professional setting and professional talent training scheme, the teachers troop construction, the school system and policy implementation, teaching management and curriculum system reform, students' moral education work system, internal quality evaluation system and management, to various factors in the deficiency existing in the process of ascension to be perfect [2].From the point of view of the implementation path, teaching diagnosis and improvement should be realized by "determining the goal", "paying attention to the elements", "discovering the insufficiency" and "improving the teaching quality" to realize the circular control of the teaching quality. From the point of view, teaching diagnosis and improvement is to further improve the quality assurance system of vocational colleges and universities, base on the characteristics of vocational colleges, constantly improve the level of information and modern quality of teaching management in colleges and universities, in order to meet the needs of the development of the times, The demand of skilled talents. 


\section{Setting principles of teaching diagnosis and improvement indexes}

The setting of teaching diagnosis and improvement targets in vocational colleges should be based on certain standards, based on the orientation and professional features of Vocational Colleges and universities, to highlight the feasibility and scientificity of the target setting, and to reflect the differences and differences between the national standards, the industry standards, the provincial standards and the different levels of the school standards, so as to ensure the establishment of the system of diagnosis and improvement. At the same time, we should adhere to the problem oriented, and should not aim high in the setting of the index, but should fit in with the reality, make the development goal of "jump one jump, reach enough", and ensure the rationality of the teaching diagnosis and improvement of the index system.

\section{The research significance of teaching diagnosis and improvement index system in vocational colleges}

Vocational colleges are institutions that train students' professional skills and provide professional and technical talents for the country. In recent years, with the continuous improvement of education and teaching level in our country, the exploration and implementation of new educational concept, consolidating and improving the educational level of vocational colleges and universities has become an important goal of the current vocational education development. The teachers of vocational colleges and universities should carry out the research of teaching diagnosis and improvement of teaching indexes in order to promote the quality of vocational colleges and universities in an all-round way. It is of great significance to strengthen the research on the teaching diagnosis and improvement index system of vocational colleges and universities for the development of vocational college education, which is embodied in the following aspects.

\subsection{Promote the status of teaching work in vocational colleges and universities}

The key to improve the quality of talent training lies in teaching. Based on this, the degree of attention to teaching in vocational colleges determines the height of its development, and also affects the achievement of the ultimate goal of the development of vocational education. However, because of the influence of traditional ideas, it is more difficult for higher vocational colleges to recruit students. Based on this phenomenon, the school leaders focus their work on the school enrollment, thus neglecting the teaching work of the school. On the long-term development of vocational colleges and universities bring greater obstacles. Therefore, vocational colleges begin to study the index system of teaching diagnosis and improvement in view of their own development problems, and carry out autonomous and regular teaching diagnosis, which ensures the teaching in the system. The centrality of academic work[3].

\subsection{It is beneficial to improve the construction of teachers and the level of education and teaching in vocational colleges and universities.}

For a long time, in the eyes of the majority of the masses, more attention has been paid to the development of general higher education and there has been a certain prejudice against vocational education, which has led many teachers of this professional level to abandon vocational colleges and universities to engage in teaching in ordinary colleges and universities. To some extent, it hinders the improvement of education and teaching level in vocational colleges. The weakness of teachers and the low professional quality of teachers are common problems in vocational colleges and universities. Therefore, in order to promote the quality management of education and teaching in vocational colleges and universities, to improve the quality of education and teaching, vocational colleges and universities continue to study the work diagnosis and index system, strengthen the construction of teachers in vocational colleges and universities, and continuously increase the input of teachers of high professional level. And to our school Teachers regularly carry out professional quality lectures, strengthen their teachers' professional qualities, strengthen their teaching staff, and create a group of qualified and excellent teachers with both professional and cultural knowledge as 
well as professional cultural literacy for vocational college education and teaching. Therefore, it can promote the improvement of education and teaching level in vocational colleges and universities.

\subsection{It is beneficial to strengthen the soft power of culture in vocational colleges and universities.}

Vocational college students are far superior to ordinary institutions of higher learning in skill mastery, but lags far behind in basic cultural knowledge. At the present stage, the standards of recruiting talents in a company are mostly all-round development talents with both cultural background and professional skills. No matter from what angle, the mode and method of cultivating talents in vocational education are not the best. Therefore, vocational colleges and universities began to study the teaching diagnosis and improvement indicators, to develop the teaching mode in which skills and cultural knowledge go hand in hand, and pay attention to improving students' cultural literacy. Promote the promotion of cultural soft power in vocational colleges and universities in terms of student employment rate and satisfaction.

\section{Research on teaching diagnosis and improvement of "Six in one" index system}

\subsection{Guarantee of professional teaching power}

Vocational colleges should provide the necessary teachers and teaching assistants according to the professional training objectives, set up professional leaders and responsible persons for professional characteristics, guarantee the proportion of teachers and students, including full-time teachers, double teachers, part-time teachers and counselors, and pay attention to the professional title of full-time teachers, education and age structure, and ensure that the professional title, education and age structure are ensured. The structure of professional teachers is rationalized.

\subsection{Professional teaching satisfaction index}

Professional teaching satisfaction is an important index to measure the teaching quality of vocational colleges and universities. The formulation of this index should meet the needs of students, parents, enterprises and other stakeholders, and be an important standard to evaluate the quality of professional teaching. This index should include: enterprise satisfaction survey, students' satisfaction with major teaching, students' satisfaction with teachers, students' satisfaction with school learning and parents' satisfaction with teaching quality. Enterprises are the verifiers of teaching quality in vocational colleges and universities, their satisfaction is focused on students' skills and knowledge, parents are indirect participants in teaching activities, and the setting of indicators should be focused on the measures to assist students and the construction of style of study. And professional and career development prospects evaluation. The setting and statistics of indicators should be based on the continuous data to ensure the continuity and objectivity of the satisfaction survey, generally taking three years' continuous data as the reference.

\subsection{Indicators of the level of social services}

The social service level of vocational colleges and universities is mainly aimed the technical skills training, vocational skills appraisal, which are carried out by enterprises, regions and communities. The contents of this indicator should include: the number of horizontal subjects and research projects in professional teaching and the guarantee of classroom funds, the annual income of foreign technical services, the number of relevant professional social and technical training, and the number of professional and off-campus vocational skills appraisals. Develop new technologies, new products or technical problems with enterprises. Regarding technical services, achievements transformation and occupational appraisal as the level of social service in vocational colleges and universities

\subsection{The level of school enterprise cooperation}

School-enterprise cooperation is an important feature of measuring the level of vocational education, and it also adapts to the important requirements of professional and industry interface in 
vocational colleges. The establishment of teaching diagnosis and improvement indicators should be focused on: the number of cooperative practice bases in schools, The number of cooperative practice bases, the number of off-campus training bases, the number of cooperative enterprises, the number of training orders in vocational colleges, the number of part-time teachers supported by enterprises and the situation of the leaders of part-time professional teaching, etc., comprehensively measure the quality of cooperation between schools and enterprises.

\subsection{Diagnosis of professional evaluation institutions}

Professional evaluation institutions are independent of the education system and stakeholders of the third party institutions and organizations, education departments and vocational colleges commissioned to provide professional advisory services, so it has a high degree of objectivity and professionalism. Vocational colleges and universities should provide the original educational diagnostic data for the professional evaluation institutions through the information platform, and provide the relevant employment, student resources and the construction of the teaching staff. On the basis of the analysis of the data, the problems existing in the teaching of vocational colleges and universities should be compared and analyzed. Identification of controllable factors, combined with the development goals of vocational colleges, the establishment of feasible, specific diagnosis and improvement indicators, to achieve the dynamic monitoring of the diagnosis and improvement of vocational colleges and universities. To provide effective guarantee for teaching diagnosis and improvement in vocational colleges and universities.

\subsection{Government diagnosis}

Government diagnosis is an important part of teaching diagnosis and improvement in vocational colleges and universities. It mainly manages and supervises the evaluation and quality evaluation of vocational colleges through the competent educational departments. Government diagnostic indicators should be mainly reflected in the macro-management level of the orientation and development planning of vocational colleges and universities. At the same time, because the government is the main investor and supervisor of vocational colleges, so, in the index system of diagnosis and improvement of vocational colleges, the idea of running a school and the use of funds should also be reflected.

In summary, a "Six-in-one" index system for teaching diagnosis and improvement is formed, as shown in Figure 1.

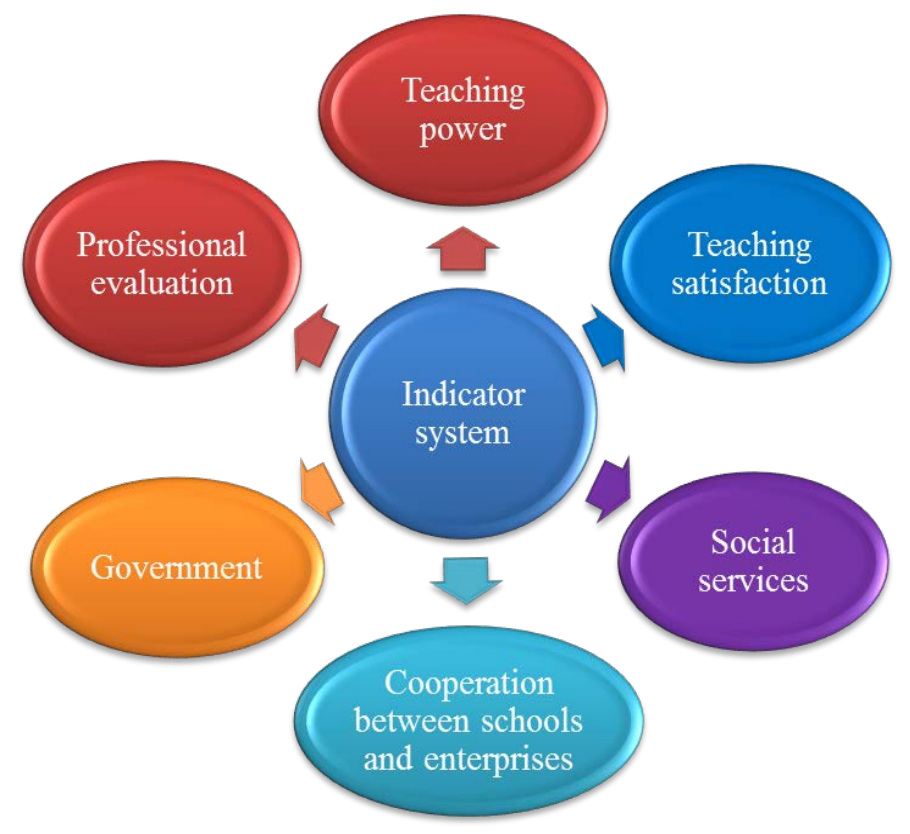

Figure 1 The index system of "Six in one" 


\section{Conclusion}

The index system of teaching diagnosis and improvement in vocational colleges is a systematic project. Vocational colleges and universities should take the initiative to carry out teaching diagnosis and improvement work, give play to the main role of teaching quality assurance [4][5]. We should actively explore the teaching diagnosis and improvement mechanism with the characteristics of our school, reasonably set up the teaching diagnosis and improvement index, construct a feasible teaching diagnosis and improvement index system, and continuously improve the quality of education and teaching in vocational colleges and universities.

\section{References}

[1] Xiangyan Wen, Junhua Dong. Construction of Teaching diagnosis and improvement Mechanism in Vocational Colleges based on ISO9001 Standard system [J]. Career, 2017 (20): 17-18.

[2] Hucheng $\mathrm{Wu}$, Yaqi Wu. Establishing Internal quality Assurance system and speeding up the Development of School connotation: a case study of Teaching diagnosis and Reform in Henan Polytechnic and Information Vocational College [J]. Henan Education (higher Education) ,2018 (04): 105-108.

[3] Jun Zhou. Study on Teaching diagnosis and improvement in Vocational Colleges based on quality improvement [J]. China's Vocational and Technical Education, 2015 (26): 35-38.

[4] Denian Wan. Reflections on the Construction of Internal quality Assurance system in higher Vocational Colleges [J]. Journal of Huanggang Vocational and Technical College, 2017,19 (2): 9-12.

[5] Hai Liu. Teaching diagnosis and improvement: the endogenous power of quality improvement in vocational colleges[J]. Vocational and Technical Education, 2016,37(18):19-23. 